\title{
ANALISIS PEWARNA RHODAMIN B PADA SAOS BAKSO TUSUK YANG BEREDAR DIBEBERAPA SEKOLAH DASAR DI KOTA MANADO
}

\author{
Balqis Muzdhalifah $^{1)}$, Sri Sudewi ${ }^{1)}$, Gayatri Citraningtyas ${ }^{1)}$ \\ ${ }^{1)}$ Program Studi Farmasi FMIPA UNSRAT Manado, 95115
}

\begin{abstract}
Rhodamin $B$ is a red synthetic dye commonly used as paper dyes, textiles or inks. Food products that are often added by Rhodamin B by irresponsible producers is sauce. The purpose of this study was to determine the presence and levels of Rhodamin B found in skewers meatballs sold in several elementary schools in Manado City using Thin Layer Chromatography and UV-Vis Spectrophotometer. The results of the study obtained that the results of the qualitative analysis using TLC obtained 5 sampels identified based on $R f$ value parameters and color visualization. Quantitative analysis of UV-Vis spectrophotometer produced Rhodamin $B$ level values for each sample which was calculated using regression formula $y=0,0726 x+$ 0,0432 and $R^{2}=0,9957$. The sample code $A 1$ was $3,443 \pm 0,080 \mu \mathrm{g} / \mathrm{mL}, B 1$ was 3,057 $\pm 0,150 \mu \mathrm{g} / \mathrm{mL}, B 2$ was 5,881 $\pm 0,170 \mu \mathrm{g} / \mathrm{mL}, C 1$ was $3,884 \pm 0,130 \mu \mathrm{g} / \mathrm{mL}$, and $C 2$ was 4,517 $\pm 0,140 \mu \mathrm{g} / \mathrm{mL}$. The conclusion in this study is that skewer meatballs circulating in several elementary schools in Manado City contains Rhodamin B.
\end{abstract}

Keywords: Rhodamin B, Skewer Meatballs Sauce, Thin Layer Chromatography, UV-Vis Spectrophotometer.

\begin{abstract}
ABSTRAK
Rhodamin B merupakan pewarna sintetik berwarna merah yang umum digunakan sebagai pewarna kertas, tekstil atau tinta. Produk pangan yang sering di tambahkan Rhodamin B oleh produsen yang tidak bertanggung jawab adalah saos. Tujuan penelitian ini adalah untuk mengetahui keberadaan dan kadar Rhodamin B yang terdapat pada saos bakso tusuk yang dijajakan pada beberapa Sekolah Dasar di Kota Manado menggunakan metode Kromatografi Lapis Tipis dan Spektrofotometer UV-Vis. Hasil penelitian yang diperoleh bahwa hasil analisis secara kualitatif menggunakan KLT diperoleh 5 sampel teridentifikasi berdasarkan parameter nilai Rf dan visualisasi warna. Analisis kuantitatif spektrofotometer UV-Vis menghasilkan nilai kadar Rhodamin B tiap sampel masing-masing yang dihitung dengan menggunakan rumus regresi $y=0,0726 x+0,0432$ dan nilai $R^{2}=0,9957$. Sampel kode A1 sebesar 3,443 $\pm 0,080 \mu \mathrm{g} / \mathrm{mL}$, B1 sebesar 3,057 $\pm 0,150 \mu \mathrm{g} / \mathrm{mL}$, B2 sebesar 5,881 $\pm 0,170 \mu \mathrm{g} / \mathrm{mL}$, C1 sebesar 3,884 $\pm 0,130 \mu \mathrm{g} / \mathrm{mL}$, dan C2 sebesar 4,517 $\pm 0,140 \mu \mathrm{g} / \mathrm{mL}$. Kesimpulan dalam penelitian ini yaitu saos bakso tusuk yang beredar di beberapa sekolah dasar di Kota Manado mengandung Rhodamin B.
\end{abstract}

Kata Kunci: Rhodamin B, Saos Bakso Tusuk, Kromatografi Lapis Tipis, Spektrofotometer UV-Vis. 


\section{PENDAHULUAN}

Makanan merupakan salah satu kebutuhan utama dalam kehidupan sehari-hari untuk memenuhi kebutuhan tubuh. Perkembangan zaman saat ini dan pengaruh ilmu pengetahuan dalam bidang pangan, makanan banyak mengandung mikroorganisme dan ditambahkan dengan bahan kimia yang dapat menyebabkan keracunan penyakit (Yulianti, 2007). Menurut BPOM.RI/NO.37/2013, bahan tambahan pangan ditambahkan pada makanan bertujuan untuk mempengaruhi sifat pangan, membentuk pangan, memberikan warna serta cita rasa dan stabilitas pangan.

Penambahan bahan pangan ke dalam makanan perlu untuk meningkatkan mutu suatu produk sehingga mampu bersaing di pasaran. Pewarna dari suatu produk makanan ataupun minuman merupakan salah satu ciri yang penting untuk menentukan kualitas makanan (Deman, 1997).

Penggunaan zat warna bertujuan untuk membuat penampilan makanan dan minuman menjadi lebih menarik. Makanan yang diwarnai dengan zat warna alami yang berasal dari tumbuhan, hewan, atau mineral, untuk memperoleh zat warna alami makanan harganya relatif mahal dan umumnya tidak stabil terhadap pengaruh cahaya dan panas. Produsen lebih menyukai warna sintetik yang relatif lebih murah dan stabil pada berbagai kondisi lingkungan dan dapat mengurangi kerugian dari produsen (Yulianti, 2007). Penelitian sebelumnya telah dilakukan di kota Manado yaitu saos bakso tusuk yang beredar di sekitar Universitas Sam Ratulangi. Hasilnya makanan yang diteliti mengandung Rhodamin B (Longdong dkk, 2017).
Pemerintah Indonesia melalui peraturan Menteri Kesehatan (Permenkes) No. 239/MenKes/Per/V/85 menetapkan Rhodamin B termasuk salah satu zat berbahaya dan dilarang digunakan pada produk pangan. Rhodamin B merupakan warna sintetik yang umum digunakan sebagai pewarna kertas, tekstil atau tinta dan penggunaannya dalam produk-produk pangan, dapat menyebabkan berbagai gangguan pada kesehatan. Zat tersebut dapat menyebabkan iritasi pada kulit dan saluran pernafasan serta bersifat karsinogenik yang dapat menyebabkan kanker. Rhodamin B dalam konsentrasi tinggi dapat menyebabkan kerusakan pada hati (Yulianti, 2008).

Dari hasil survei lapangan pada tanggal 2 Oktober 2018 dijumpai jajanan bakso tusuk yang beredar di Sekolah Dasar kota Manado. Umumnya jajanan bakso tusuk tidak nikmat tanpa adanya saos. Saos adalah bahan pelengkap yang terbuat dari tomat. Saos merupakan salah satu bahan penyedap dan penambah rasa pada makanan. Saos yang beredar mempunyai warna yang mencolok yaitu berwarna merah yang menarik perhatian terutama kalangan anak-anak. Banyak penemuan kandungan Rhodamin B pada saos yang berwarna merah digunakan oleh produsen makanan dan peredarannya meluas pada kebanyakan produsen yang ditemukan (Longdong dkk, 2017).

Berdasarkan uraian diatas maka perlu dilakukan penelitian mengenai analisis zat warna Rhodamin B pada saos bakso tusuk yang dijual pada beberapa Sekolah Dasar di Kota Manado.

\section{METODE PENELITIAN}

Alat

Alat-alat gelas (pyrex), hot plate (NESCO LAB), kertas whatman ukuran $15 \mathrm{x} 15 \mathrm{~cm}$, timbangan analitik (KERN AC $22-4 \mathrm{M}$ ), 
chamber (pyrex), waterbath (Julabo TW12), centrifuge (CLEMENTS GS 150),

plat KLT F-254, spektrofotometer Uv-Vis (Shimadzu 00780), Komputer pengolah data.

\section{Bahan}

$\mathrm{HCl} 0,1 \mathrm{~N}$, Rhodamin $\mathrm{B}$, etil asetat, metanol p.a, natrium sulfat anhidrat, amonia p.a, sampel saos bakso tusuk.

\section{Prosedur Kerja}

\section{Pengambilan Sampel}

Sampel saos bakso tusuk diambil dari empat Sekolah Dasar yang berbeda yang berada tepatnya di Kota Manado. Dimana setiap Sekolah Dasar diambil pada tiga penjual berbeda pula. Selanjutnya setiap sampel saos bakso tusuk yang telah diambil dikemas. Kemudian setiap sampel dari masing-masing pedagang akan diteliti apakah mengandung Rhodamin B dan berapa kadar yang terkandung didalamnya.

\section{Analisis Kualitatif Rhodamin B}

\section{a. Pembuatan larutan uji}

Sampel saus tomat ditimbang sebanyak 5 gram, ditambahkan 4 tetes $\mathrm{HCl}$ 0,1 $\mathrm{N}$ dan 5-10 $\mathrm{mL}$ metanol. Dipanaskan di atas penangas air \pm 5 menit, disaring dengan kertas saring yang berisi natrium sulfat anhidrat. Diambil filtrat dan dimasukkan ke dalam botol vial $5 \mathrm{~mL}$.

\section{b. Pembuatan larutan baku}

Ditimbang sebanyak $\pm 5 \mathrm{mg}$ pewarna Rhodamin B baku (pembanding), dilarutkan dalam $10 \mathrm{~mL}$ metanol, dikocok hingga larut. Uji Identifikasi sampel Disiapkan plat KLT, dilakukan penotolan larutan A dan B secara terpisah, kemudian dimasukkan ke dalam chamber yang telah dijenuhkan dengan etil asetat: metanol: amonia (4:1:1). Setelah proses elusi selesai, amati noda dibawah UV $254 \mathrm{~nm}$ dan $366 \mathrm{~nm}$, noda merah berfluoresensi kuning menunjukkan adanya Rhodamin B.

\section{Analisis Kuantitatif Rhodamin B}

a. Pembuatan larutan Rhodamin B $\mathbf{1 0 0}$ $\mu \mathrm{g} / \mathrm{mL}$

Ditimbang $1 \mathrm{mg}$ pewarna Rhodamin B dimasukkan kedalam labu terukur $10 \mathrm{~mL}$ didalam labu terukur ditambahkan $\mathrm{HCl} 0,1$ $\mathrm{N}$ secukupnya dan dikocok hingga homogen. Kemudian larutan dicukupkan dengan $\mathrm{HCl} 0,1 \mathrm{~N}$ hingga garis tanda kemudian dihomogenkan.

\section{b. Penentuan panjang gelombang maksimum larutan Rhodamin B}

Dipipet 0,2 mL larutan Rhodamin B dengan menggunakan pipet volum dan dimasukkan kedalam labu terukur $10 \mathrm{~mL}$ (konsentrasi $2 \mu \mathrm{g} / \mathrm{mL}$ ), lalu ditambahkan $\mathrm{HCl} 0,1 \mathrm{~N}$ sampai garis tanda dan dihomogenkan. Diukur serapan maksimum pada panjang gelombang 400-800 nm dengan menggunakan blangko. Blangko yang digunakan adalah $\mathrm{HCl} \mathrm{0,1} \mathrm{N}$.

\section{c. Penentuan operating time}

Dipipet $0,2 \mathrm{~mL}$ larutan kerja Rhodamin B $100 \mu \mathrm{g} / \mathrm{mL}$ dan dimasukkan kedalam labu terukur $10 \mathrm{~mL}$ (konsentrasi $2 \mu \mathrm{g} / \mathrm{mL}$ ), lalu ditambahkan $\mathrm{HCl} 0,1 \mathrm{~N}$ sampai kegaris tanda dan dihomogenkan. Diukur pada panjang gelombang maksimum yang diperoleh sampai 30 menit.

\section{d. Pembuatan Kurva Baku Rhodamin B}

Dibuat larutan baku Rhodamin B dengan konsentrasi $100 \mu \mathrm{g} / \mathrm{mL}$, Dari 
larutan tersebut dibuat larutan baku 10 $\mu \mathrm{g} / \mathrm{mL}$, Selanjutnya dubuat satu seri larutan baku dengan konsentrasi masingmasing 2, 4, 6, 8, dan $10 \mu \mathrm{g} / \mathrm{mL}$, sebagai pelarut digunakan $\mathrm{HCl} 0.1 \mathrm{~N}$. Dilakukan $3 \mathrm{x}$ pengulangan pada masing-masing konsentrasi.

\section{Uji Kuantitatif Sampel}

Ditimbang 1 gr sampel lalu dimasukkan ke dalam cawan penguap lalu ditambahkan 7 tetes $\mathrm{HCl} 0,1 \mathrm{~N}$ dan ditambahkan $15 \mathrm{~mL}$ metanol. Dipanaskan diatas waterbath selama 15 menit. Disentrifugasi selama 4 menit. Lalu ditambahkan Na-sulfat anhidrat secukupnya kemudian disaring dan diamati dengan spektrofotometer UV-Vis. Pengukuran dilakukan sebanyak $3 x$ pengulangan.

\section{Analisis Data Rhodamin B Untuk Sampel}

Analisis data kadar Rhodamin B dalam sampel dengan menggunakan kurva kalibrasi dengan persamaan regresi : $y=a x+b$.

\section{HASIL DAN PEMBAHASAN}

\section{Pengambilan Sampel}

Sampel saos bakso tusuk diambil dari empat Sekolah Dasar yang berbeda yang berada tepatnya di Kota Manado. Pengambilan Sampel berdasarkan pembagian wilayah utara, selatan, timur dan barat Kota Manado. Diantaranya Sekolah Dasar Cokroaminoto 01 (A), Sekolah Dasar Negeri 11 (B), Sekolah Dasar Negeri 54 (C) dan Sekolah Dasar GMIM Nafiri (D), dimana setiap Sekolah Dasar diambil pada tiga pedagang yang berbeda.

\section{Analisis Kualitatif KLT}

Berdasarkan hasil pengukuran sampel saos bakso tusuk menggunakan kromatografi lapis tipis diperoleh data. Data dapat dilihat pada Tabel 1.

Tabel 1. Data analisis kualitatif

\begin{tabular}{|c|c|c|c|c|c|}
\hline $\begin{array}{c}\text { Kode } \\
\text { Sampel }\end{array}$ & $\begin{array}{c}\text { Paramet } \\
\text { er } \\
\text { Hasil } \\
\text { KLT }\end{array}$ & $\begin{array}{c}\text { UV } \\
254 / 3 \\
66\end{array}$ & $\begin{array}{c}\text { Jara } \\
\mathrm{k} \\
\text { Nod } \\
\mathrm{a} \\
(\mathrm{cm})\end{array}$ & $\begin{array}{c}\text { Nilai } \\
\text { Rf }\end{array}$ & $\begin{array}{c}\text { Keterang } \\
\text { an }\end{array}$ \\
\hline A1 & Kuning & $\begin{array}{c}\text { Fluore } \\
\text { sensi } \\
\text { Orang } \\
\text { e }\end{array}$ & 6,9 & 0,8625 & Positif \\
\hline A2 & Kuning & - & 6,2 & 0,775 & Negatif \\
\hline A3 & Kuning & - & 5,9 & 0,7375 & Negatif \\
\hline B1 & Merah & $\begin{array}{c}\text { Fluore } \\
\text { sensi } \\
\text { Orang } \\
\text { e }\end{array}$ & 7,1 & 0,8875 & Positif \\
\hline B2 & Merah & $\begin{array}{c}\text { Fluore } \\
\text { sensi } \\
\text { Orang } \\
\text { e }\end{array}$ & 7,5 & 0,9375 & Positif \\
\hline B3 & Kuning & - & 4,7 & 0,5875 & Negatif \\
\hline $\mathrm{C} 1$ & Kuning & $\begin{array}{c}\text { Fluore } \\
\text { sensi } \\
\text { Orang } \\
\text { e }\end{array}$ & 6,9 & 0,8625 & Positif \\
\hline $\mathrm{C} 2$ & Kuning & $\begin{array}{c}\text { Fluore } \\
\text { sensi } \\
\text { Orang } \\
\text { e }\end{array}$ & 7,6 & 0,95 & Positif \\
\hline C3 & Kuning & - & 1,8 & 0,225 & Negatif \\
\hline D1 & Merah & - & 3,9 & 0,4875 & Negatif \\
\hline D2 & Kuning & - & 5,7 & 0,7125 & Negatif \\
\hline D3 & Kuning & - & 2,7 & 0,3375 & Negatif \\
\hline Rhodamin B & $\begin{array}{l}\text { Merah } \\
\text { Terang }\end{array}$ & $\begin{array}{c}\text { Fluore } \\
\text { sensi } \\
\text { Orang } \\
\text { e }\end{array}$ & 7,1 & 0,8875 & Positif \\
\hline
\end{tabular}

Hasil penelitian diperoleh bahwa ada satu sampel yang teridentifikasi mengandung Rhodamin B dari 12 sampel yang diteliti, yaitu pada sampel B1 hal ini dibuktikan dengan perhitungan nilai Rf ke -12 sampel. Sampel B1 menyamai nilai Rf dari Rhodamin B dengan jarak noda pada plat sebesar 7,1. Menurut Lipsy (2010), nilai Rf dapat dijadikan bukti dalam mengindentifikasi suatu senyawa, yang mana jika hasil identifikasi nilai Rf memiliki nilai yang sama maka senyawa tersebut dapat dikatakan memiliki karakteristik yang sama atau mirip, sedangkan jika nilai Rf-nya berbeda maka senyawa 
tersebut dapat dikatakan bukan senyawa yang sama.

Berdasarkan identifikasi parameter warna sinar UV terdapat 5 sampel yang memeperlihatkan warna orange pada lampu UV dengan panjang gelombang 254/366. Hal ini sejalan dengan pendapat Ditjen POM (2001) menyatakan bahwa sampel makanan yang mengandung Rhodamin B akan mudah diamati, jika secara visual akan memperlihatkan warna merah muda dan jika dilihat dengan sinar UV akan berfluoresensi orange atau kuning.

Hasil yang diperoleh dari analisis kualitatif untuk memastikan keberadaan Rhodamin B dalam sampel dibuktikan dengan melakukan analisis kuantitatif menggunakan spektrofotometer bertujuan mengetahui kadar Rhodamin B yang terdapat pada sampel. Analisis kuantitatif dilakukan pada 5 sampel yakni A1, B1, B2, C1 dan C2 sampel ini diambil berdasarkan nilai Rf dan identifikasi parameter warna yang ditunjukkan hasil analisis kualitatif menggunakan Kromatografi Lapis Tipis. Hal ini dilakukan untuk membuktikan 2 parameter yang berbeda dalam pengidentifikasian menggunakan KLT.

\section{Analisis Kuantitatif}

\section{Penentuan Panjang Gelombang Maksimum}

Penentuan panjang gelombang maksimum dilakukan dengan menggunakan spektrofotometer UV-Vis pada daerah paanjang gelombang 400-800 nm dan konsentrasi yang dipakai $2 \mu \mathrm{g} / \mathrm{mL}$ sehingga diperoleh panjang gelombang $495 \mathrm{~nm}$ pada panjang gelombang ini menghasilkan absorbansi 0,211. Hasil penentuan dapat dilihat pada Gambar 1.

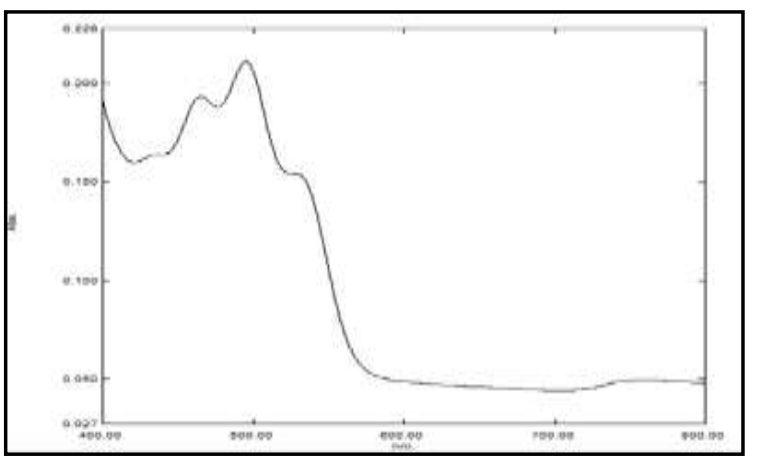

Gambar 1. Kurva absorbansi Rhodamin B dalam konsentrasi $2 \mu \mathrm{g} / \mathrm{mL}$ dengan pelarut $\mathrm{HCl} 0,1 \mathrm{~N}$

\section{Penentuan Operating Time}

Pada penelitian ini penentuan operating time ditentukan dengan mengukur absorbansi pada panjang gelombang maksimum yang diperoleh dari data panjang gelombang maksimum yaitu $495 \mathrm{~nm}$ dengan konsentrasi yang digunakan $2 \mu \mathrm{g} / \mathrm{mL}$ dengan rentang waktu 1-30 menit dengan hasil absorbansi 0,21 Hal ini menunjukkan bahwa berdasarkan kestabilannya waktu optimal untuk pembacaan absorbansi adalah pada menit ke-1 sampai menit ke-30.

\section{Kurva Kalibrasi Larutan Baku Rhodamin B}

Kurva kalibrasi larutan baku Rhodamin B yang dibuat degan konsentrasi $10 \mu \mathrm{g} / \mathrm{mL}$. Selanjutnya dibuat satu seri larutan baku dengan konsentrasi masing-masing 2, 4, 6, 8, $10 \mu \mathrm{g} / \mathrm{mL}$ dan diukur pada panjang gelombang $495 \mathrm{~nm}$ menggunakan $\mathrm{HCl} 0,1 \mathrm{~N}$ sebagai pelarut atau blanko.

Berdasarkan hasil pembuatan kurva dengan menggunakan metode Spektrofotometer yang menghubungkan konsentrasi dengan absorbansi, diperoleh persamaan linear $\mathrm{y}=0,0726 \mathrm{x}+0,0432$ dengan koefisien korelasi $\mathrm{r}=0,9957$. Hasil koefisien korelasi diatas telah memenuhi kriteria penerimaan yaitu $\geq 0,98$ (Harmita, 2004).

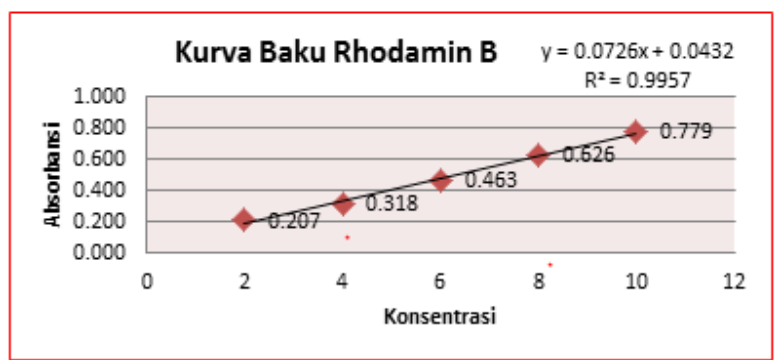

Gambar 2. Kurva Kalibrasi Larutan Baku Rhodamin B 


\section{Hasil Pengujian Sampel}

Sampel yang teridentifikasi dengan analisis kualitatif KLT secara nilai Rf maupun parameter warna dilakukan pengujian menggunakan spektrofotometer untuk mengetahui kadar Rhodamin B yang ada pada sampel. Data hasil pengujian sampel dapat dilihat pada Tabel 2.

Tabel 2. Data absorbansi pada tiap sampel.

\begin{tabular}{|c|c|c|c|c|}
\hline \multirow{2}{*}{ Sampel } & \multicolumn{2}{|c|}{ Absorbansi } & \multirow{2}{*}{$\begin{array}{l}\text { Absorbansi } \\
\text { Rata-Rata }\end{array}$} & \multirow{2}{*}{$\begin{array}{l}\text { Kadar Rhodamin } \\
\mathrm{B}(\mu \mathrm{g} / \mathrm{mL}) \pm \mathrm{SD}\end{array}$} \\
\hline & 1 & 2 & & \\
\hline $\mathrm{A} 1$ & 0,245 & 0,344 & 0,294 & $2,876 \pm 0,08$ \\
\hline B1 & 0,32 & 0,212 & 0,266 & $4,212 \pm 0,15$ \\
\hline B2 & 0,463 & 0,479 & 0,471 & $7,269 \pm 0,17$ \\
\hline $\mathrm{C} 1$ & 0,365 & 0,287 & 0,326 & $4,914 \pm 0,13$ \\
\hline $\mathrm{C} 2$ & 0,468 & 0,277 & 0,372 & $3,661 \pm 0,14$ \\
\hline
\end{tabular}

Dari tabel tersebut nilai kadar yang didapat dengan menggunakan rumus regresi $\mathrm{y}=0,0726 \mathrm{x}+0,0432$ dan nilai $\mathrm{R}^{2}=0,9957$. Hasil perhitungan pada sampel A1 sebesar $3,443 \pm 0,080 \mu \mathrm{g} / \mathrm{mL}$, B1 sebesar 3,057 \pm $0,150 \mu \mathrm{g} / \mathrm{mL}$, B2 sebesar 5,881 $\pm 0,170$ $\mu \mathrm{g} / \mathrm{mL}, \mathrm{C} 1$ sebesar 3,884 $\pm 0,130 \mu \mathrm{g} / \mathrm{mL}$, dan C2 sebesar 4,517 $\pm 0,140 \mu \mathrm{g} / \mathrm{mL}$. Nilai kadar menunjukkan keberadaan dan banyaknya Rhodamin B yang ada dalam sampel yang telah dianalisa. Sampel yang teridentifikasi berdasarkan nilai kadar berada pada sampel yang dijual di 3 Sekolah Dasar menurut pembagian wilayah yaitu sampel A Sekolah Dasar Cokroaminoto 011 pedagang, B Sekolah Dasar Negeri 112 pedagang serta sampel C Sekolah Dasar Negeri 542 pedagang, ini menunjukkan bahan tambahan pangan terutama pewarna yang dilarang penyebarannya masih luas di beberapa pedagang.

Rhodamin B adalah salah satu pewarna sintetis yang digunakan pada industri tekstil zat pewarna ini ditetapkan sebagai zat yang dilarang penggunaanya pada makanan. Rhodamin B bersifat karsinogenik sehingga dalam penggunaan jangka panjang akan menyebabkan kanker. Penelitian telah dilakukan untuk uji toksistas Rhodamin B terhadap mencit dan tikus dengan injeksi subkutan dan secara oral. Rhodamin B dapat menyebabkan karsinogenik pada tikus ketika diinjeksi subkutan, yaitu timbul sarcoma lokal. Sedangkan secara IV didapatkan $\mathrm{LD}_{50}$ $89,5 \mathrm{mg} / \mathrm{kg}$ yang ditandai dengan gejala adanya pembesaran hati, ginjal, dan limfa diikuti perubahan anatomi berupa pembesaran organnya (MerckIndex, 2006).

\section{KESIMPULAN}

1. Dari hasil penellitian analisis kualitatif menggunakan Kromatografi Lapis Tipis menunjukkan adanya 5 sampel yang teridentifikasi mengandung Rhodamin B yaitu sampel A1, B1, B2, C1, dan C2 yang tersebar pada beberapa pedagang.

2. Hasil perhitungan kadar pada analisis kuantitatif terdapat 5 sampel dengan nilai masing-masing A1 sebesar 3,443 $\pm 0,080$ $\mu \mathrm{g} / \mathrm{mL}, \mathrm{B} 1$ sebesar 3,057 $\pm 0,150 \mu \mathrm{g} / \mathrm{mL}$, B2 sebesar 5,881 $\pm 0,170 \mu \mathrm{g} / \mathrm{mL}, \mathrm{C} 1$ sebesar 3,884 $\pm 0,130 \mu \mathrm{g} / \mathrm{mL}$, dan $\mathrm{C} 2$ sebesar 4,517 $\pm 0,140 \mu \mathrm{g} / \mathrm{mL}$. Nilai kadar ini menunjukkan berapa banyak kandungan Rhodamin B dalam sampel.

\section{SARAN}

Perlu dilakukan pengawasan rutin oleh instansi terkait terhadap makanan dan minuman yang beredar di masyarakat.

\section{DAFTAR PUSTAKA}

Badan POM RI. 2013. Peraturan Kepala Badan POM RI No. 37 Tahun 201. Tentang Batas Maksimum Penggunaan Bahan Tambahan Pangan Pewarna. Badan POM RI, Jakarta. 
Deman, J.M. 1997.Kimia Makanan. Penerbit ITB, Bandung.

Ditjen POM RI. 2001. Metode Analisis PPOMN. Ditjen POM, Jakarta.

Harmita, 2004. Petunjuk Pelaksanaan Validasi Metode dan Cara Perhitungannya. Majalah Ilmu Kefarmasian [serial on internet]. Vol 1 (3). [Dikutip 23 maret 2018].

Lipsy, P. 2010. Thin Layer Chromatography Characterization of the Active Ingredients In Excerdrin And Anacin. Departement of Chemistry and Chemical Biology. Steven Intitute of Technology, USA.

Longdong, G, Jemmy, A, Novel, K. 2017. Analisis zat pewarna Rhodamin B pada saos bakso tusuk yang beredar di sekitar kampus Universitas Sam Ratulangi. Jurnal ilmiah farmasi. Vol 6 (4). Universitas Sam Ratulangi, Manado.

MerckIndex. 2006. Chemistry Constant Companion. Now with a New Addition. Ed $14^{\text {th }}$. Merck \& Co. Inc. White house station.NJ, USA.

Yulianti, N. 2007. Awas Bahaya dibalik Lezatnya Makanan. CV. ANDY Offset, Yogyakarta.

Yulianti, N. 2008. Racun di Sekitar Kita. Edisi Pertama. CV. ANDY Offset, Yogyakarta. 